\title{
An Experimental Study of the Tribological Characteristics of Engine and Gear Transmission Oils
}

\author{
Sreten Perić1,* - Bogdan Nedić2 - Dragan Trifković ${ }^{1}$ - Mladen Vuruna ${ }^{1}$ \\ 1 University of Defence, Military Academy, Serbia \\ 2 University of Kragujevac, Faculty of Engineering, Serbia
}

During the past few decades, special attention has been devoted to developing modern instruments and methods of monitoring the tribomechanical characteristics of technical systems. Today, various physical, chemical and tribological methods are used in tribomechanical systems diagnosis. Scientific experience in technical system exploitation and maintenance has shown that the most effective way to predict failure is based on parameters that are reliable indicators of wear. Analysis of oil samples, which contain particles due to the wear process, enables an evaluation of the tribology condition of the system in the early phases of its use.

This paper deals with tribological tests that are part of the oil analysis and are used to access the condition of the system. Furthermore, the results of experimental research on the tribological characteristics of the oil sampled from engines and gear transmissions of the vehicles (Mercedes 0 345, PUCH 300GD and PINZGAUER 710M) are shown. All of these road vehicle were in regular use by the Serbian armed forces. The performed research has revealed some significant changes in the tribological characteristics of oil for engine and gear transmission lubrication.. These changes directly depend on the condition of the entire engine and transmission elements, i.e. depend on their functional characteristics. The presented method of oil analysis should contribute to an early detection of failures due to friction and wear processes in vehicle engines and reduce the need for preventive maintenance.

Keywords: oil condition monitoring, lubricants, engine oils, dynamic modelling

\section{INTRODUCTION}

The main goal in tribology is to provide a thin layer of low shear strength medium at the surface contact between loaded solids in relative motion. This is to reduce friction and guard against surface wear. The tribochemical behaviour of the surface-lubricant interface is quite important. The goal of lubrication is to provide a layer of a different material between the surfaces in contact that reduces the friction force between them, either by being softer than the surfaces, or by being a coherent liquid lubricant trapped between the two surfaces by their relative movement [1] and [2]. Using the model in this paper, it is possible to identify the status of the tribomechanical system and to reduce the need for preventive maintenance by using adequate sampling methods and undertaking tribological studies [3] to [5].

The primary role of the lubricant is to reduce the negative effects of tribological processes related to friction, wear, and increases in temperature in tribomechanical systems, therefore all types of maintenance include lubrication as a very important part of the whole maintenance process.

On the other hand, the lubricant is a key constituent of the contact conjuction that carries information about the state of the whole system, from the point of view of tribological and other ageing processes. Therefore, analysis of the lubricant oil, based on a properly defined program, represents a very effective method for monitoring the state of technical systems, providing early warning signs of potential problems that could lead to failure and breakdown of the technical systems. Like the mechanical components, the lubricant itself can also change and this leads to losses of lubricating properties, such as reduced viscosity, contamination, degradation, loss of load carrying capacity, etc. [6] to [9].

A vehicle as a complex system comprises many load bearing and power transmitting contacts. These are composed of elements that participate in the power and torque transmission from the engine, through the transmission (gearbox, differential and other systems), to the important sub-systems in a vehicle [10]. Since it is a complex tribomechanical system, the transmission gearbox is split into eight main tribological systems. The tribosystems of the transmission gearbox are: tapered roller bearings, spur gears, synchronization elements, splashing, shifting elements, differential gear, sealing elements, and needle bearings [4].

This analysis indicates that the tribological characteristics of a complex tribomechanical system cannot be considered in a simple way. Thus, it is not easy to establish reliable methods, as well as to determine diagnostic parameters, for evaluating the analysed system.

There are a variety of reasons for failures of real systems and so far there has been no reliable generic method for predicting the lifetime of complex systems [4] and [11]. Wear, fatigue, and mechanical vibration 
are some examples of the underlying reasons for contact failures. Gohar and Rahnejat highlight these modes of failure [1]. Fatigue spalling life prediction methods for concentrated contacts are also noted there. There are various underlying mechanisms for failure by wear due to lack of a coherent lubricant film [12]. Vibration is often the cause of failure, as it causes fatigue or wear. There are many examples of this, such as those highlighted for a valve train system by Teodorescu et al. [13] and in rotor and spindle bearings by Aini et al. [14].

Lubricant oil monitoring during use is one of the most important procedures in tribomechanical system diagnostics, due to the importance of the oil's functions in this system. The advantage of this procedure is that information about the functionality of the system's components is obtained without stopping and dismantling the vehicle.

Modern trends in diagnostics have moved towards an increasing promotion of oil monitoring, which has resulted in an increased interest in oil producers and users. The reasons lie primarily in increasing reliability and effectiveness, as well as in economic considerations and protection of the environment [15] to [18].

There is growing interest in the use of coated contact surfaces in general. Hard wear resistant coatings lead the way, particularly for highly loaded contacts such as cam-follower pairs. This choice is also based on the increased fatigue resistance of coatings [19] to [21]. However, hard wear resistant coatings such as DLC (diamond-like-carbon) can exfoliate through fractures at high shear forces and can also be oleophobic.

Due to an ever growing demand to reduce oil consumption and thus the amount of oil in mechanical systems, but also because of the increased severity of the contact conditions, many of systems need to operate under boundary lubrication and starvedlubrication conditions [2] and [22].

\section{TRIBOLOGICAL CHARACTERISTICS OF OIL}

The development of tribology as an interdisciplinary science based on experimental investigations and the varied experimental equipment and devices (tribometers) needed to carry this out have contributed to creating tribometry as a particular area of experimental research [23] to [25].

Identification of tribological processes, as a precondition to diagnosis of the conditions of real tribomechanical systems, can be carried out by:
- tracking functional behaviour of a real technical system and

- model investigations.

Tracking the performance of a real tribomechanical system includes a narrow and strictly oriented long-term study without the possibility of varying and examining the influence of input parameters in a wider range.

However, using model investigations enables a large range of data to be obtained, indicating the condition of a realistic system and enabling the prediction of its further behaviour with some reliability. In order to conduct these studies it is necessary to take samples from a real system and to simulate the contact conditions as well. In addition, the differences between real tribomechanical systems and studies under model conditions must be taken into account before making conclusions based on tribometric studies. On the other hand, most tribological characteristics are determinated using defined standard tests, as shown in Table 1.

For these purposes, some of the standard commercial tribometers such as Falex, Timken, Plint, Koehler, SRV, etc. can be used.

Table 1. Lubricant tribological characteristics tests

\begin{tabular}{|c|c|}
\hline Standard & Contact geometry \\
\hline \multicolumn{2}{|c|}{ Wear Preventive Characteristics } \\
\hline $\begin{array}{l}\text { ASTM D2670 } \\
\text { ASTM D4172 }\end{array}$ & $\begin{array}{l}\text { Pin and Vee Block } \\
\text { (Four-Ball) }\end{array}$ \\
\hline \multicolumn{2}{|c|}{ Extreme Pressure Properties } \\
\hline $\begin{array}{l}\text { ASTM D2782 } \\
\text { ASTM D2783 } \\
\text { ASTM D3233 } \\
\text { IP } 240\end{array}$ & $\begin{array}{l}\text { Block on Ring } \\
\text { Four Balls } \\
\text { Pin and Vee Block } \\
\text { Block on Ring }\end{array}$ \\
\hline \multicolumn{2}{|c|}{ Friction characteristics } \\
\hline ASTM D 5183 & Four-Ball \\
\hline \multicolumn{2}{|c|}{$\begin{array}{l}\text { Tribological behaviour of the lubricant in devices with real mechanica } \\
\text { elements }\end{array}$} \\
\hline ASTM D5182 & FZG - Gear Test Rig \\
\hline
\end{tabular}

A new measurement equipment for tribological studies have been developed and produced over the past few years. A new methodology of investigation is also being developed. The measuring system, applied to determine the tribological characteristics of the tribomechanical system elements is shown in Figs. 1 and 2. It is composed of [11]:

- a TPD-93 Tribometer for normal force, frictional force, and frictional coefficient measurements;

- thermopairs for temperature measurements of oil and elements in contact;

- a PQ-2000 particle quantifier; 
- a Microscope for wear parameters measurements (length, width, and depth of worn zone);

- Talysurf 6, a computerized measuring device for surface topography and wear parameter measurements.

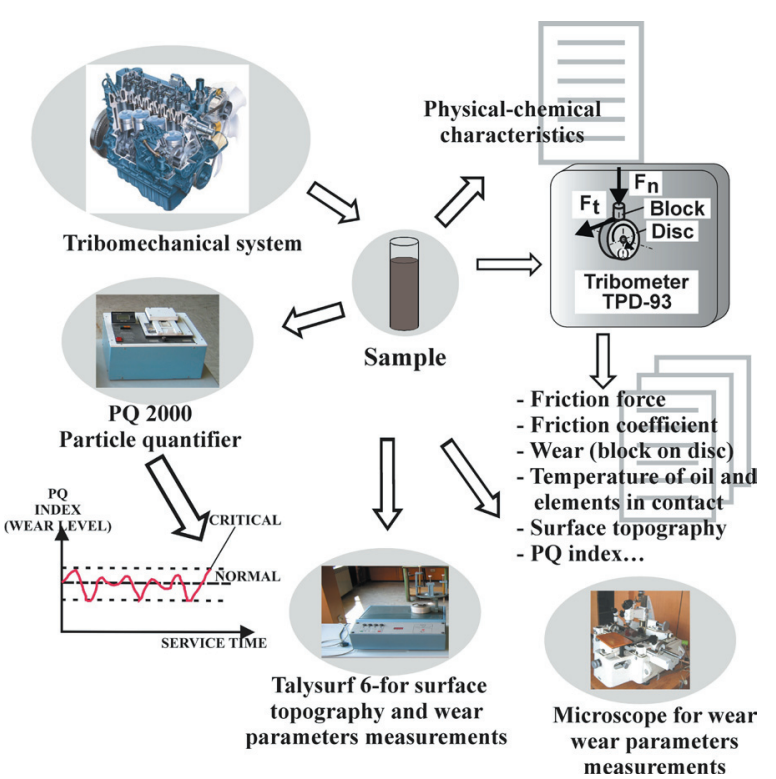

Fig. 1. Model of the investigation procedure of lubricant tribological characteristics during use

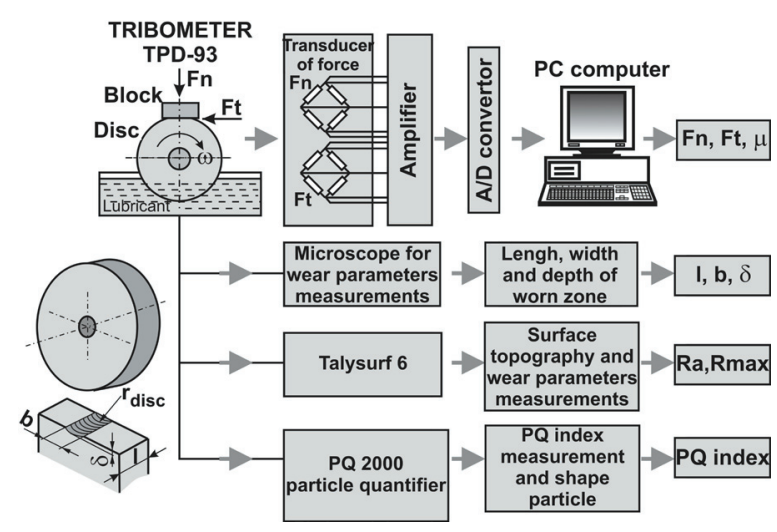

Fig. 2. Measuring system applied for the determination of tribological characteristics

As shown in Fig. 1, the investigation procedure for determining the tribological characteristics of lubricant during use includes:

- oil sampling from a real tribomechanical system [26] and [27];

- determination of physical-chemical characteristics;

- $\quad$ analysis of wear products in the oil;

- measuring tribological characteristics of the tribomechanical system in a model investigation using sampled oil as the lubricant.
It should be pointed out that these investigations imply a previous determination of contact characteristics such as:

- contact geometry;

- intensity and character of external loads;

- type (continual, cyclical, etc.) and velocity of motion;

- temperature of elements in contact;

- lubrication method.

The elements of the contact pair are specified by a detailed analysis of a real tribomechanical system. These elements need to have strictly defined characteristics such as material type, hardness, surface condition, and so on.

The examinations were performed using a "block on disc" tribometer with linear contacts typical for elements in a mechanical power transmission system such as gearboxes, gear couplings, rolling bearings, etc. After a certain period of time the linear contact is transformed into a surface contact due to the process of wearing. This type of contact is characteristic for cylindrical mechanical elements such as a strokecylinder pair in an internal combustion engine.

As a great number of the elements in contact in the tribomechanical systems of a mechanical power transmission and engine have both linear and surface types of contact, the applied testing model using the "block on disc" tribometer can be used with sufficient accuracy to make a comparison of the tested oils.

\section{RESULTS OF THE STUDY OF THE TRIBOLOGICAL CHARACTERISTICS OF OIL}

Oil was sampled from engines and transmission gearboxes of the vehicles (Mercedes O 345 as vehicle 1, PUCH $300 \mathrm{GD}$ as Vehicle 2 and PINZGAUER $710 \mathrm{M}$ as Vehicle 3) that were in use. The tribological characteristics of the oil were examined in accordance with standard methods. The analysis was performed using both fresh oil and oil used in the engines and transmission gearboxes of vehicles. Testing of oil samples was carried out in accordance with commonly defined criteria for the quality of used oil. The research was conducted through a periodic oil sampling from the engines and transmission gearboxes of the vehicles listed above. During oil sampling, special attention was paid to the positions of the sampling, which enabled each sample to be a representative one. Each sample was taken from the "live zone," i.e. the zone closer to the elements in contact. Special attention was also paid to preserving the sample from contamination, both in the sampling phase and in the manipulation phase, according to the prescribed 
procedures. These measures provided a very high level of purity to all elements in the sampling chain as well as for the separation of samples in a way that does not perturb the integrity of the data that the samples carry.

Results obtained during the tests contain information about the friction coefficient, friction force, width and depth of the wear track, wear shape of the block's contact surface, change in the friction coefficient and temperature during the time of contact, block's and disc's surface topography parameters before and after the testing, etc. To investigate the dynamics of the contact process, the force and friction coefficient signals were recorded continuously for later processing.

Figs. 3 to 5 show the friction coefficient of the engine oil samples against vehicle mileage (distance in traveled kilometres). It can be seen that the mean value of the friction coefficient between the block and the disc is in the 0.0684 to 0.101 range, using the tested engine oil from all vehicles. It can be concluded that increase in vehicle mileage for Vehicle 1 (using SAE 10W-40, API Classification CF engine oil) causes a gradual decrease in the friction coefficient. The increase in vehicle mileage for Vehicle 2 (using SAE 10W-40 API SG/CE engine oil) causes an initial decrease and later increase in the friction coefficient. The engine oil from Vehicle 3 (SAE 30/S3) shows an initial increase and later decrease in the friction coefficient.

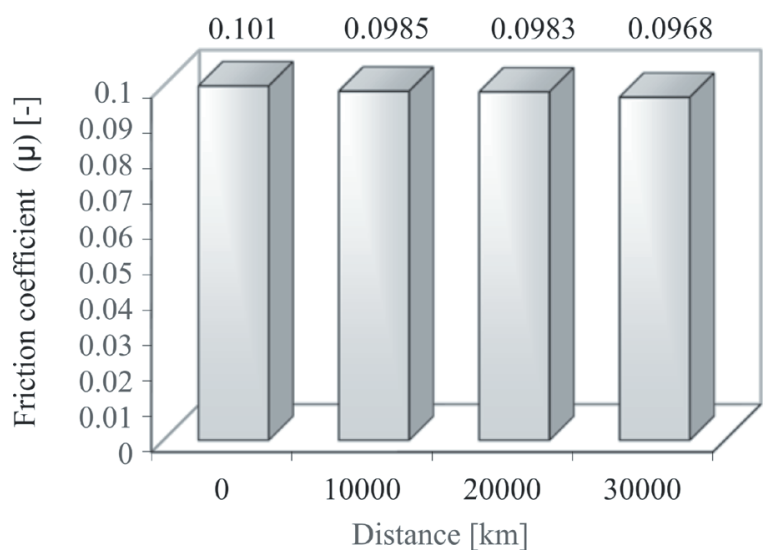

Fig. 3. Change in the friction coefficient of Vehicle 1 engine oil

Zinc dialkyldithophosphate (ZDDP) additives are arguably the most successful lubricant additives ever invented [28]. They were introduced over 60 years ago, have been in continuous use ever since, and are still being employed in practically all engine oils and many transmission oils.

The high value of the friction coefficient $(\mu=$ 0.101) of fresh engine oil SAE 10W-40, API CF (zero sample), used in Vehicle 1, which is higher than the friction coefficient of used engine oil, was measured because of the presence of ZDDP. The ZDDP content of engine oil is different from transmission oil due to the engine conditions.

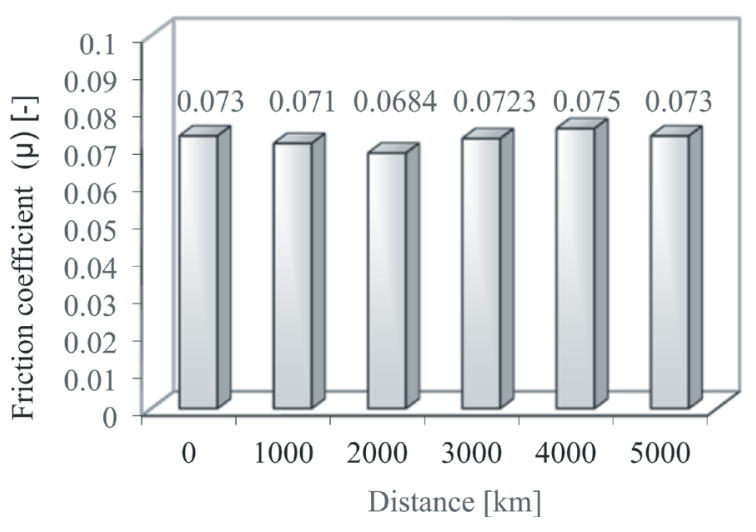

Fig. 4. Change in the friction coefficient of Vehicle 2 engine oil



Fig. 5. Change in the friction coefficient of Vehicle 3 engine oil

The ZDDP additive has three important functions: it serves as an antioxidant, anti-corrosion, and antiwear additive. At low temperatures (below $100{ }^{\circ} \mathrm{C}$ ), the ZDDP has an antioxidant function. If applied at higher temperatures, which is the case for engine oils, it thermally decomposes and the resulting products have an antioxidant function. The temperature of this degradation process is dependent on the alkyl groups present (and the metal cation) but usually occurs somewhere between 130 and $230^{\circ} \mathrm{C}$. Three main ways that ZDDP acts as an anti-wear agent have been proposed: (a) by forming a mechanically protective film; (b) by removing corrosive peroxides or peroxyradicals; (c) by "digesting" hard and thus abrasive iron oxide particles [28]. When ZDDPs react with hydroperoxides and peroxy radicals they generate products which themselves act as effective oxidation 
inhibitors [29], making ZDDP a highly efficient inhibitor.

Figures 6, 7 and 8 show the changes in wear width of sampled engine oils versus vehicle mileage.

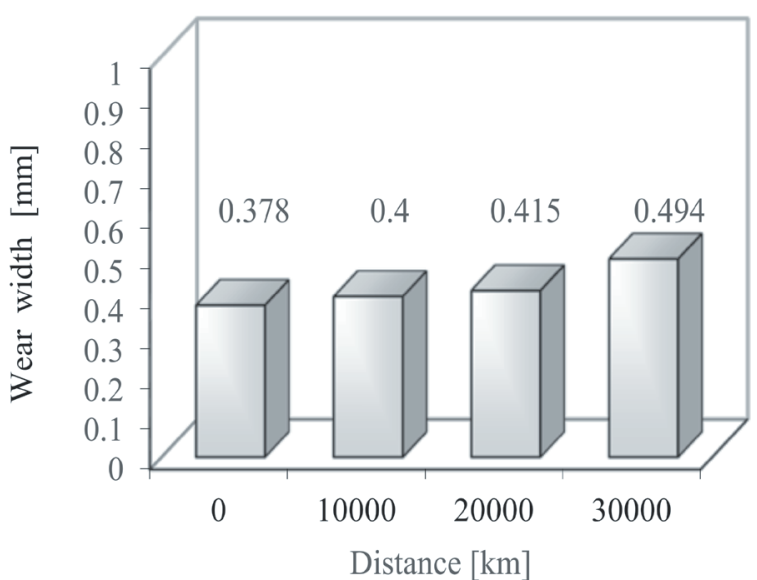

Fig. 6. Change in the wear width of Vehicle 1 engine oil versus mileage

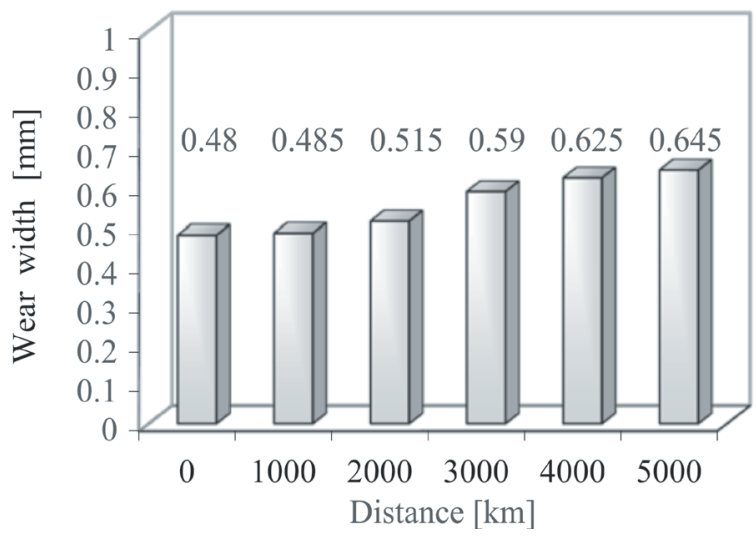

Fig. 7. Change in the the wear width of Vehicle 2 engine oil versus mileage

The increase in mileage causes an increase in the disc wear width for the tested engine oils from the all three vehicles. The maximum value of the disc wear width is $0.494 \mathrm{~mm}$ (Vehicle 1), $0.645 \mathrm{~mm}$ (Vehicle 2) and $0.610 \mathrm{~mm}$ (Vehicle 3). An increase in wear width in the initial period can be explained by the wellknown bathtub curve diagram, which corresponds to the initial use of the engine with fresh oil. The approximately constant growth in disc wear width as a function of mileage is caused by the wear products increase in the lubricant and the gradual degradation of the lubricant's characteristics during the test. Surface roughness of the discs and blocks were measured, prior to the experiments, using Talysurf 6 .
Figs. 9 to 11 show the changes in the friction coefficient of the transmission oil (gearbox oil) samples against vehicle mileage.

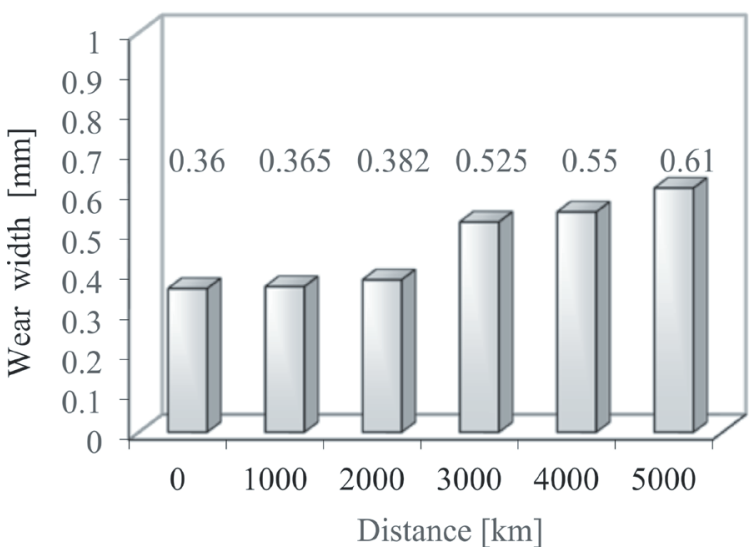

Fig. 8. Change in the wear width of Vehicle 3 engine oil versus mileage

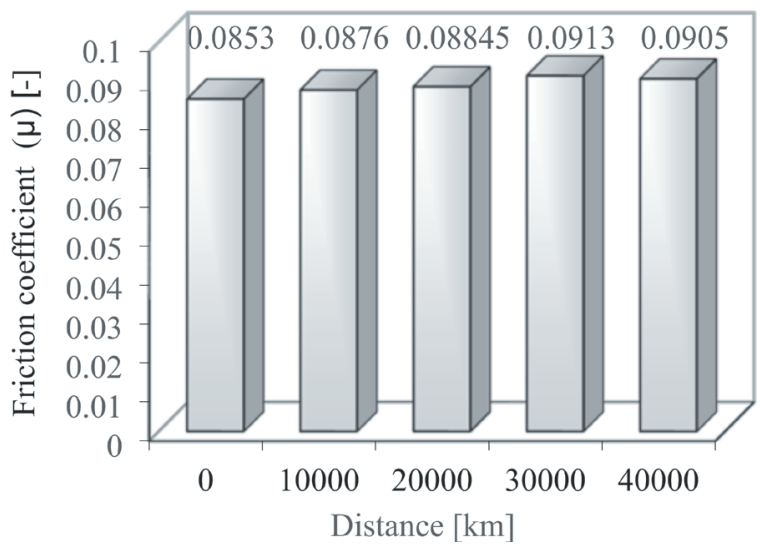

Fig. 9. Change in the friction coefficient of Vehicle 1 transmission oil

The mean values of the friction coefficient between the block and the disc, using the tested transmission oils, are in the 0.058 to 0.0987 range. The increase in mileage causes a gradual increase in the friction coefficient of the transmission oil used in Vehicle 1, while the friction coefficient of Vehicle 2 transmission oil gradually decreases. In the case of the transmission oil used in Vehicle 3, the friction coefficient initially decreases and then increases with mileage.

Fig. 9 shows that the friction coefficient of the samples of used transmission oil ATF (Automatic transmission fluid) Prista (from Vehicle 1) is higher than the friction coefficient of the zero samples of the same oil.

Higher temperatures lead to reactions between the additives from the oil and the lubricated surface, 
thus ZDDP decomposes into free radicals. This slows the oxidation process of transmission oil down. Free radicals were found to be present in the used transmission oil (Prista ATF) and were formed as previously described. The free radicals do not influence the decrease in friction and wear, because of the ZDDP antioxidant function.

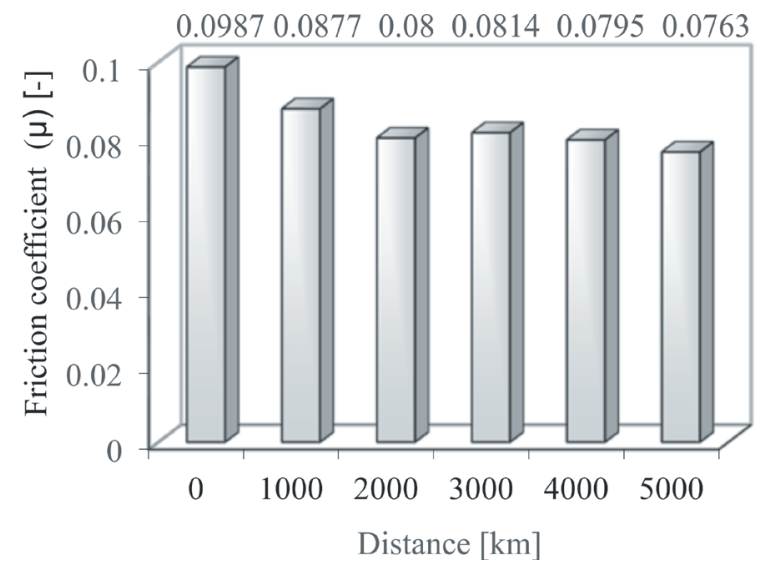

Fig. 10. Change in the friction coefficient of Vehicle 2 transmission oil

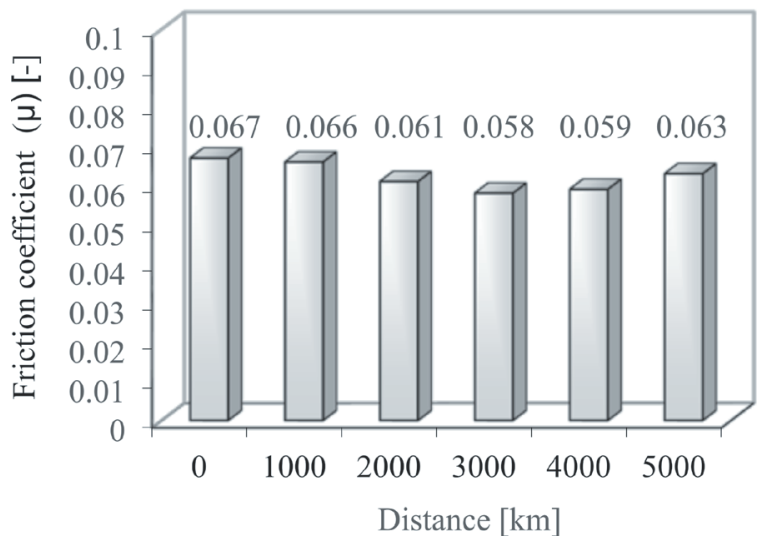

Fig. 11. Change in the friction coefficient of Vehicle 3 transmission oil

From Fig. 10, it can be seen that the friction coefficient for the zero sample of transmission fluid (Vehicle 2) is higher than that for the used transmission oil samples. This result can be explained by the structure of the lubricant, which contains a sulfur-phosphorous EP (extreme pressure) antiwear additive. During contact between surfaces, the phosphorus in the additive reacts with the metal at 700 ${ }^{\circ} \mathrm{C}$ and forms a metal-phosphide layer, which protects the surface from wear. At the same time, the sulfur in the additive reacts with the metal at $900{ }^{\circ} \mathrm{C}$ forming metal sulfides, which have the same anti-wear function. The layers formed on the contact surfaces cause the high values of the friction coefficient.



Fig. 12. Change in wear width of Vehicle 1 transmission oil versus mileage

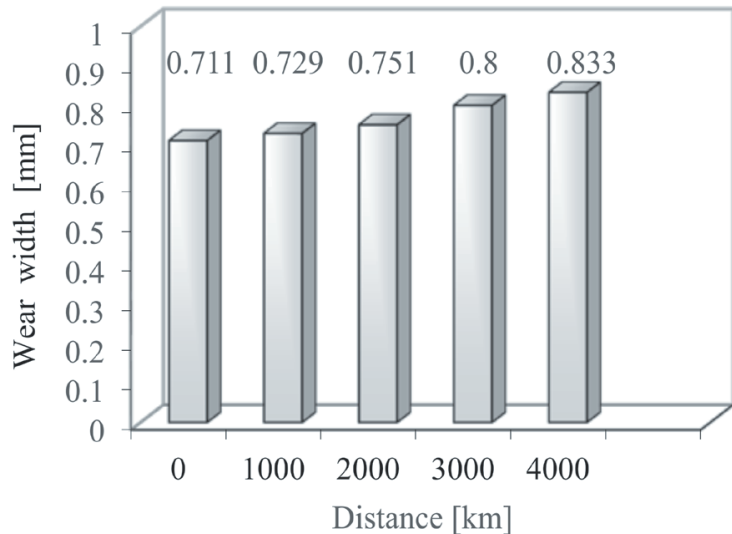

Fig. 13. Change in wear width of Vehicle 2 transmission oil versus mileage

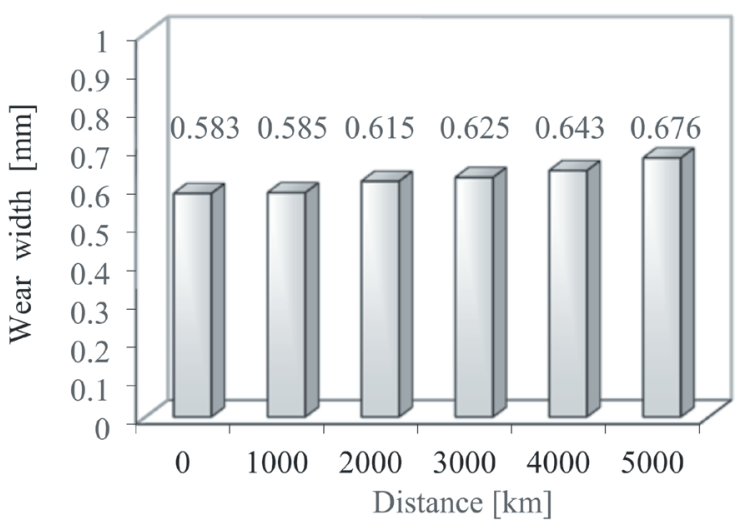

Fig. 14. Change in wear width of Vehicle 3 transmission oil versus mileage

Used UAMS transmission oil contains polar compounds formed in the oxidation chemical reactions of additives and metals, especially at 
elevated operating temperatures. In this way, the polar compounds formed are bonded to the block and disc metal surface, forming a layer of metal soap. A formed lubricating layer prevents the contact of block and disc surfaces, resulting in the transition from an initial boundary lubrication to an elastohydrodynamic lubrication. The results are less friction and wear, as well as more sliding of surfaces.

Figs. 12 to 14 show the changes in wear width of the sampled transmission oil versus vehicle mileage.

The increase in mileage causes the increase in disc wear width for the tested transmission oils from all three vehicles. The maximum values of the disc wear width are $0.752 \mathrm{~mm}$ (Vehicle 1), $0.833 \mathrm{~mm}$ (Vehicle 2) and $0.676 \mathrm{~mm}$ (Vehicle 3).

\section{CONCLUSIONS}

Based on the experimental investigation, the following conclusions can be summarized:

1. In order to choose the correct lubricant, it is necessary to know its formulation (base oil and additive package), physical-chemical properties, lubrication conditions, and the characteristics of the technical system in which it is used.

2. There are changes in the working and tribological properties of all components of the vehicle during use: the speed and degree of degradation processes depend on the operating conditions. Changes that occur in the components of the vehicle and in the lubricants form under the same conditions and are mutually correlated.

3. An effective program of condition assessment of lubricants includes: testing of the physicalchemical properties of lubricants, testing of the content of contaminants, testing of the content and the types of products, as well as testing of the tribological properties of lubricants.

4. The model tests ensure the repeatability of sampling and testing procedures, comparability of results, and assessment of the same elements under different test conditions.

5. The changes in the physical-chemical and tribological properties of the lubricating oil from the vehicle engine and transmission gearbox are directly dependent on the functional characteristics of all the elements of the tribomechanical system.

6. The method of oil analysis, presented above, should enable an early detection of failure due to the development of friction and wear processes during operation.
7. The presented method for the examination of the tribomechanical characteristics of oils under model conditions, together with testing their physical-chemical characteristics, will be used for the development of a new universal diagnostic model. This diagnostic model will allow the condition of components in the mechanical power transmission systems and vehicle engines to be determined.

\section{REFERENCES}

[1] Gohar, R., Rahnejat, H. (2008). Fundamentals of Tribology. Imperial College Press, London, DOI:10.1142/p553.

[2] Bhushan, B. (2013). Introduction to Tribology. John Wiley \& Sons, New York, DOI:10.1002/9781118403259.

[3] Peric, S., Nedic, B. (2010). Monitoring oil for lubrication of tribomechanical engine assemblies. Journal of the Balkan Tribological Association, vol. 16, no. 2, p. 242-257.

[4] Wienecke, D., Bartz, W. (2001). Automobile Transmission Gears as Tribological Systems. Tribology Transactions, vol. 44, no. 3, p. 484-488, DOI: $10.1080 / 10402000108982485$.

[5] Vähäoja, P., Välimäki, I., Roppola, K., Kuokkanen, T., Lahdelma, S. (2008). Wear Metal Analysis of Oils. Critical Reviews in Analytical Chemistry, vol. 38, no. 2, p. 67-83, DOI:10.1080/10408340701804434.

[6] Babic, M. (2004). Lubricants Monitoring. University of Kragujevac, Faculty of Mechanical Engineering, Kragujevac. (in Serbian)

[7] Peric, S. (2006). Influence of Tracked Vehicle Transmission Gear Exploitation Method upon Physical and Chemical Characteristics of Lubricants, MSc thesis. University of Belgrade, Faculty of Mechanical Engineering, Belgrade. (in Serbian)

[8] Barnes, M. (2002). Oil Viscosity - How It's Measured and Reported. Practicing Oil Analysis. Magazine, Nov.-Dec.

[9] Mang, T. (2000). Future Importance of Base Oils in Lubricants. Proceedings of $12^{\text {th }}$ International Colloquium, Tribology Plus, Esslingen, p. 23-35.

[10] Beuf, D. (2001). Used Oil Analysis and Equipment Monitoring. Texaco Training, Chevron-Texaco Technology, Ghent.

[11] Peric, S. (2009). The Development of a Method of Diagnosis the Condition from the Aspect of PhysicalChemical and Tribological Characteristics of Lubricating Oils of Vehicles, PhD Thesis. University of Defence, Belgrade. (in Serbian)

[12] Archard, J.F., Ernest J.G. (1980). Wear Control Handbook. Amer Society of Mechanical Engineers, New York.

[13] Teodorescu, M., Kushwaha, M., Rahnejat, H., Taraza, D. (2005). Elastodynamic transient analysis of a four- 
cylinder valvetrain system with camshaft flexibility. Journal of Multi-body Dynamics, vol. 219, no. 1, p. 1325, DOI: $10.1243 / 146441905 X 9962$.

[14] Aini, R., Rahnejat, H., Gohar, R. (1995). An experimental investigation into bearing-induced spindle vibration. Proceedings of the Institution of Mechanical Engineers, Part C: Journal of Mechanical Engineering Science, vol. 209, no. 2, p. 107-114, DOI:10.1243/ PIME_PROC_1995_209_130_02.

[15] Peric, S., Nedic, B., Vuruna, M. (2009). Monitoring physical and chemical characteristics oil for lubrication. Journal Tribology in Industry, vol. 31, no. 3-4, p. 5966.

[16] Liu, C., Nemoto, S., Ogano, S. (2003). Effect of soot properties in diesel engine oils on frictional characteristics. Tribology Transactions, vol. 46, no. 1, p. 12-18, DOI:10.1080/10402000308982593.

[17] Markova, V., Myshkin, K., Ossia, V., Kong, H. (2007). Fluorescence sensor for characterization of hydraulic oil degradation. Tribology in Industry, vol. 29, no. 1-2, p. 33-36.

[18] Godfrey, D., Herguth, W.R. (1995). Physical and chemical properties of industrial mineral oils affecting lubrication. Lubrication Engineering, vol. 51, no. 5, p. 397.

[19] Teodorescu, M., Rahnejat, H. (2007). Mathematical modelling of layered contact mechanics of cam-tappet conjunction. Applied Mathematical Modelling, vol. 31, no. 11, p. 2610-2627, DOI:10.1016/j.apm.2006.10.019.

[20] Jaffar, J.M. (1989). Asymptotic behaviour of thin elastic layers bonded and unbonded to a rigid foundation. International Journal of Mechanical Sciences, vol. 31, no. 3, p. 229-235, DOI:10.1016/0020-7403(89)901136.

[21] Naghieh, G.R., Rahnejat, H., Jin, Z.,M. (1999). Characteristic of frictionless contact of bonded elastic and viscoelastic layered solids. Wear, vol. 232, no. 2, p. 243-249, DOI:10.1016/S0043-1648(99)00152-0.

[22] Velkavrh, I., Kalin, M., Vižintin, J. (2008). The performance and mechanisms of DLC-coated surfaces in contact with steel in boundary-lubrication conditions - a review. Strojniški vestnik - Journal of Mechanical Engineering, vol. 54, no. 3, p. 189-206.

[23] Rac, A. (1991). Tribology. University of Belgrade, Faculty of Mechanical Engineering, Belgrade. (in Serbian)

[24] Ripa, M., Spanu, C., Ciortan, S. (2008). Characterization of hydraulic oils by shear stability and extreme pressure tests. Tribology in Industry, vol. 30, no. 3-4, p. 48-54.

[25] Neale, M.J. (2001). The Tribology Handbook. Butterworth-Heinemann publications, Oxford.

[26] Lee, M.P., Priest, M., Stark, S.M., Wilkinson, J.J., Lindsay Smith, J.R., Taylor, I.R., Chung, S. (2006). Extraction and tribological investigation of top piston ring zone oil from a gasoline engine. Proc. IMechE, J. Engineering Tribology, vol. 220, no. 3, p. 1-10, DOI:10.1243/13506501JET148.

[27] Yatsutomi, S., Maeda, Y., Maeda, T. (1981). Kinetic approach to engine oil: 1-analysis of lubricant transport and degradation in engine system. Industrial and Engineering Chemistry Product Research and Development, vol. 20, no. 3, p. 530-536, DOI:10.1021/ i300003a020.

[28] Spikes, H. (2004). The history and mechanisms of ZDDP. Tribology Letters, vol. 17, no. 3, p. 469-489, DOI:10.1023/B:TRIL.0000044495.26882.b5.

[29] Al-malaika, S., Coker, M., Scott, G. (1988). Mechanism of antioxidant action: Nature of transformation products of dithiophosphates-Part 1. Their role as antioxidants in polyolefins. Polymer Degradation and Stability, vol. 22, no. 2, p. 147-159, DOI:10.1016/01413910(88)90038-9. 